\title{
Men's education on planning and encouraging breastfeeding improves the mothers' performance and exclusive breastfeeding: a randomized controlled trial
}

\section{Farideh Panahi}

Shahid Beheshti University of Medical Sciences School of Nursing and Midwifery

masoumeh simbar ( $D$ msimbar@gmail.com )

Shahid Beheshti University of Medical Sciences School of Nursing and Midwifery

https://orcid.org/0000-0003-2843-3150

farzaneh rashidi fakari

North Khorasan University of Medical Sciences

Razieh Lotfi

Alborz University of Medical Sciences

Mitra Rahimizadeh

Alborz University of Medical Sciences

\section{Research}

Keywords: Education, Exclusive Breastfeeding

Posted Date: November 4th, 2020

DOI: https://doi.org/10.21203/rs.3.rs-96629/v1

License: (c) (1) This work is licensed under a Creative Commons Attribution 4.0 International License.

Read Full License 


\section{Abstract}

Background: men's participation is crucial for promoting of breastfeeding. There are a few studies on the effectiveness of father's education on the nursery performance. Therefore, this study aims to assess the mothers' performance following father's education on breastfeeding.

Method: This randomized clinical trial was performed on 76 fathers in two groups of control (38 men) and intervention (38 men) in a selected health center in Iran. They were spouses of primiparous women; fathers of a healthy, single neonates. Two groups of intervention and control were selected using randomized sampling method. The tools for data collection were: a "Demographic and Maternal-Infant Information Questionnaire", and a "Fathers' support for Breastfeeding Assessment Tool", a "Checklist to Assess Mothers' Breastfeeding Performance" and an "Exclusive Breastfeeding Questionnaire". The intervention was: fathers' education about "breastfeeding" and "the ways of support including encouragement and planning for breastfeeding". The education was performed in the intervention group in two sessions with one-week interval. Fathers in the control group did not receive the education. Mothers' breastfeeding performance, father's support for breastfeeding and exclusive breastfeeding was compared before and after intervention, and between groups after four months' intervention. Data was analyzed using SPSS 26 .

Results: Between groups comparison showed, before intervention, the mean scores for breastfeeding performance was not significantly different between two groups $(P=0.7)$. However, after the intervention, it was higher in the interventional group comparing to the control group ( $T$ test; $p<0.001)$. Intra-groups comparison demonstrated, after intervention, the improvement was not seen after 4 months in the control group $(p=0.6)$, while there was a significant improvement in the intervention group comparing to before intervention (Paired test; $p<0.001$ ).

Conclusion: The results showed that father's education improves breastfeeding performance of nursery mothers. Since, breastfeeding is an important factor for maternal-infant health, providing fathers' participation education to promote breastfeeding programs leads to long and effective exclusive breastfeeding.

Trial Registration: IRCT201508248801N10. Registered 31 August 2016.

\section{Background}

Breast milk provides all nutrients and necessary energy during first months of life and Breastfeeding is the best choice to guarantee neonate's growth and development (1). Exclusive breastfeeding is recommended to begin from the first hour after birth and continued to six months (2). Breast milk guarantees sensual and cognitive development of the neonate and protect neonate against infectious and chronic disease (3). Breastfeeding prevents the rate of diabetes and weight loss. Exclusive breastfeeding also decrease the diarrhea and pneumonia and helps to rapid rehabilitation after infection (4). 
Highest rates of breastfeeding are reported in Sub-Sahara Africa and south Asia as well as some parts of Latin America. In majority of developing countries, the prevalence of breastfeeding is about 20 percent. This rate is lower 1 percent in UK and about 27 percent in USA, 35 percent in Norway and 16 percent in Sweden. Besides, despite of the importance of breastfeeding in low- and middle-income countries, only 37 percent of neonates of under 6 months have exclusive breastfeeding $(4,5)$. In developing countries, duration of breastfeeding is shorter than in developing countries. The rate of exclusive breastfeeding in Iran is 53 percent (6). In a review article mean of duration of exclusive breastfeeding was 4.1 months and the prevalence were 4 and 5 until 6 months and 65 and 54 percent respectively (7). World goals for exclusive breastfeeding should reach to 60 percent until 2030 (8)

Therefore, despite of the importance of breastfeeding, its prevalence is not optimistic. Although breastfeeding is partly an instinctive behavior but it is also accounted as an acquisitive behavior that its quality and continuity can be improved by education and support $(9,10)$. Mothers, especially those with the first time experience of breastfeeding may have no adequate knowledge and self-efficacy for breastfeeding (11). Therefore, health providers can improve the maternal breastfeeding performance by a comprehensive education $(12,13)$. Several factors such as maternal age, occupation and number of children; including fathers' participation are shown to be related with breastfeeding behavior of mothers (14-16).

Father's participation in different reproductive stages including prenatal, parturition, postpartum and neonatal care were studied. One of the most important roles of fathers is their support of breastfeeding mothers $(17,18)$. Fathers' participations demonstrated to be related with success and continuity of breastfeeding $(19,20)$. But it is documented that fathers have no adequate information about the importance of breastfeeding and how to support their nursing wife (21). It seems fathers' education about the importance of breastfeeding and the effects of breast milk on growth and development of neonate as well as on maternal physical and mental health can improve their participation and support $(22,23)$.

There are a few studies about the effects of fathers' education on the breastfeeding performance. This study aimed to compare breastfeeding performance of mothers after a fathers' education program about breastfeeding.

\section{Method}

\section{Design of the study}

This was a randomized clinical trial study on 38 fathers attended to a health center in Karaj-Iran.

The participants: Seventy-six fathers were participated in the studies that were randomly selected for the intervention (38 fathers) or control (38 fathers) groups. They were recruited from attendees to the health centers for receiving postpartum care services, and had 3 to 5 days old neonates. The inclusion criteria were: men with primiparous wife, lack of known medical and mental diseases, speaking in Persian with a 
healthy single neonate without any prohibition for breastfeeding. The exclusion criteria were: hospitalization of neonate, dying of infant or a family member during the study, or couple's separation during the study, taking medicine which prevents breastfeeding, feeding neonate with other milks except maternal milk, using pacifier and unwanted pregnancy.

\section{Sampling}

Sample size was calculated 76 subjects (38 subjects for each control and intervention group) considering $95 \%$ confidence interval and power 80 percent.

$n=\frac{\left(z_{1-\alpha / 2}+z_{1-\beta}\right)^{2} *\left[p_{1}\left(1-p_{1}\right)+p_{2}\left(1-p_{2}\right)\right]}{\left(p_{1-} p_{2}\right)^{2}}$

Randomized sampling was performed to select the health centers and also for devoting the subjects of the study to control or intervention groups using excel randomization option.

Tools of the study: Tools for data collection were: "Demographic and Maternal-Infant Information Questionnaire", and a "Fathers' support for Breastfeeding Assessment Tool", a "Checklist to Assess Mothers' Breastfeeding Performance" and an "Exclusive Breastfeeding Questionnaire". The intervention was: fathers' education about "breastfeeding" and "the ways of support including encouragement and planning for breastfeeding".

\section{Maternal-Infant Information Questionnaire}

It has 14 questions about demographic and maternal and infants' information. Validity of the questionnaire was assessed and confirmed by 10 midwifery and reproductive health experts.

\section{Fathers' support for Breastfeeding Assessment Tool}

The questionnaire has 12 items to assess fathers' encouragement and planning for nursing mothers' nutrition and rest and their involvement in household issues and the infant care. The items were assessed by a 5 level likert scale from never to always that scored 1 to five. The total scores were calculated and converted to percent. Validity of the questionnaire was assessed by 10 reproductive health experts. The validity was confirmed by S-CVI $=0.76$ and S-CVR $=0.79$ respectively. Reliability of the questionnaire was assessed by using test retest stability assessment method. Fifteen men with two-week interval filled the questionnaire and Pearson 0.86 confirmed the reliability of the questionnaire.

\section{Checklist to Assess Mothers' Breastfeeding Performance}

This checklist has 26 items to assess breastfeeding performance and status, and with "yes" or "no" responses. The total score was calculated and converted to percent. Validity of the questionnaire was assessed by 10 reproductive health experts. The validity was confirmed by S-CVI $=0.78$ and S-CVR $=0.83$ respectively. Reliability of the checklist was confirmed by using intra-rater stability assessment method. 
Breastfeeding performance of 15 mothers was rated by two researchers and ICC $=0.72$ confirmed the stability of the checklist. Internal consistency assessment showed Cronbach's $a=0.78$ of the tool.

\section{Exclusive Breastfeeding Questionnaire}

It had 3 questions about inclusive or inclusive breast feeding.

\section{Procedure of the study}

Before intervention, both groups completed the demographic and maternal-infant information questionnaire and the fathers' involvement in planning and encouragement for breastfeeding questionnaire (FIPEB-6). Then fathers (with the mothers) in the intervention group were educated about breastfeeding. they were educated using face to face method, in two sessions, with 40 minutes' duration and one-week interval. In the control group only mothers were educated with the same instruction.

Fathers in the intervention group were educated about breast milk composition, the importance and the benefits of exclusive breastfeeding for maternal and neonatal health, the correct positions for breastfeeding, their critical role in promoting and continuing of breastfeeding. They were also advised about the ways of their participation; such as mothers' encouragement, or planning for a regular exclusive breastfeeding, or serving mothers in household tasks to free adequate time for nursing mothers' rest. They were explained about for mother and infant.

Four months later, all fathers in both groups completed the questionnaires to assess breastfeeding status and also the checklists to assess breastfeeding performance were completed.

This study was approved by the ethics committee of Shahid Beheshti University of Medical sciences. The participants had the option to exclude any time they want. Besides, all participants were explained about the confidentiality of the information. An informed written consent was given by all participants.

Data were analyzed by using SPPS 22, as well as statistical tests such as $t$ test, Chi2, ANOVA and repeated measure ANOVA.

\section{Results}

All 76 fathers in the intervention and control groups completed the study and there was no drop of samples in the study (Fig. 1).

Demographic and maternal and neonate information of participants in two groups are compared in the Table 1. The results showed two groups were not significantly different regarding the demographic and any other possible confounding variables $(p<0.05)$. 
Table 1

Comparison of demographic and maternal-infant health characteristics of $\mathrm{n}$ two groups of the study

\begin{tabular}{|c|c|c|c|c|c|c|}
\hline \multirow[t]{2}{*}{$\begin{array}{l}\text { Groups } \\
\text { Variables }\end{array}$} & & \multicolumn{2}{|c|}{ Control $(n=38)$} & \multicolumn{2}{|c|}{$\begin{array}{l}\text { Intervention }(\mathrm{n}= \\
\text { 38) }\end{array}$} & \multirow{2}{*}{$\begin{array}{l}\text { Test } \\
(\mathrm{P} \\
\text { Value })\end{array}$} \\
\hline & & Mean & SD & Mean & SD & \\
\hline \multicolumn{2}{|l|}{ Age of father(Years) } & 29.36 & 8.01 & 29.31 & 5.92 & 0.49 \\
\hline \multicolumn{2}{|l|}{ Age of Mother(Years) } & 22.26 & 6.63 & 21.73 & 6.65 & 0.06 \\
\hline \multicolumn{2}{|l|}{ Weight of Neonate (gr) } & 3644 & 12.4 & 3684 & 5.4 & $0.6^{* *}$ \\
\hline \multicolumn{2}{|l|}{ High of Neonate(Cm) } & 49.76 & 2.40 & 48.92 & 3.74 & $0.2^{* *}$ \\
\hline \multicolumn{2}{|l|}{ Apgar of 1 minutes } & 8.73 & 3.34 & 8.84 & 3.36 & $0.08^{\star * *}$ \\
\hline \multirow{2}{*}{\multicolumn{2}{|c|}{ Apgar after 5 minutes }} & 9.92 & 0.59 & 9.97 & 0.23 & $0.1^{* \star *}$ \\
\hline & & No & $\%$ & No & $\%$ & Test \\
\hline \multirow[t]{3}{*}{ Fathers' education } & Primary School & 12 & 31.61 & 12 & 31.61 & \multirow[t]{3}{*}{$0.6^{* * *}$} \\
\hline & High school & 8 & 21.05 & 13 & 34.22 & \\
\hline & Academic & 18 & 47.34 & 13 & 34.22 & \\
\hline \multirow[t]{3}{*}{ Mothers' education } & Primary School & 2 & 5.26 & 3 & 7.85 & \multirow[t]{3}{*}{$0.97^{* \star}$} \\
\hline & High school & 17 & 44.71 & 16 & 42.1 & \\
\hline & Academic & 19 & 50.05 & 19 & 50.05 & \\
\hline \multirow[t]{4}{*}{ Fathers' occupation } & Unemployed & 1 & 2.63 & 2 & 5.26 & \multirow[t]{4}{*}{0.13} \\
\hline & Farmer, Worker & 5 & 13.1 & 6 & 15.76 & \\
\hline & Clerk & 11 & 29.01 & 10 & 26.37 & \\
\hline & Shopper & 21 & 55.26 & 20 & 52.61 & \\
\hline \multirow[t]{2}{*}{ Maternal Occupation } & House wife & 36 & 94.8 & 38 & 100 & \multirow[t]{2}{*}{$0.06^{*}$} \\
\hline & employed & 2 & 5.3 & 0 & 0 & \\
\hline \multirow[t]{2}{*}{ House hold monthly income } & adequate & 7 & 18.42 & 9 & 23.68 & \multirow[t]{2}{*}{$0.1^{*}$} \\
\hline & Not adequate & 31 & 81.58 & 29 & 76.32 & \\
\hline \multirow{3}{*}{$\begin{array}{l}\text { Initiation of breastfeeding after } \\
\text { birth }\end{array}$} & Immediate & 14 & 36.88 & 16 & 42.1 & \multirow[t]{3}{*}{$0.3^{*}$} \\
\hline & $\begin{array}{l}\text { During the first } \\
\text { hour }\end{array}$ & 9 & 23.68 & 9 & 23.68 & \\
\hline & After one hour & 15 & 39.47 & 13 & 34.21 & \\
\hline
\end{tabular}




\begin{tabular}{|c|c|c|c|c|c|c|}
\hline \multirow{2}{*}{$\begin{array}{l}\text { Groups } \\
\text { Variables }\end{array}$} & & \multicolumn{2}{|c|}{ Control $(n=38)$} & \multicolumn{2}{|c|}{$\begin{array}{l}\text { Intervention( } \mathrm{n}= \\
\text { 38) }\end{array}$} & \multirow{2}{*}{$\begin{array}{l}\text { Test } \\
(\mathrm{P} \\
\text { Value) }\end{array}$} \\
\hline & & Mean & SD & Mean & SD & \\
\hline \multirow[t]{2}{*}{ Neonate sex } & female & 22 & 57.9 & 21 & 55.26 & \multirow[t]{2}{*}{$0.2^{*}$} \\
\hline & Male & 16 & 42.1 & 17 & 44.71 & \\
\hline
\end{tabular}

The comparison of father's support of breastfeeding in two groups of the study before and after intervention demonstrated a significant higher support after intervention in the educational intervention group $(P<0.001)$. Also, intragroup comparison showed a significant decrease of fathers' support after four months $(P<0.001)$, while a significant increase of fathers' support of fathers occurred after four mounts $(P<0.001)($ Table2).

Table 2

The comparison of father's support of breastfeeding in two groups of the study before and after intervention

\begin{tabular}{|llllll|}
\hline Groups & \multicolumn{2}{l}{ Control $(\mathrm{n}=38)$} & \multicolumn{2}{l|}{ Intervention $(\mathrm{n}=38)$} & Independent T test \\
\cline { 2 - 5 } Time & Mean & SD & Mean & SD & Between groups \\
\hline Before intervention & 76.45 & 17.75 & 70.65 & 17.61 & $\mathrm{P}=0.1$ \\
\hline Four months after intervention & 60.87 & 9.99 & 92.8 & 7.02 & $\mathrm{P}<0.001$ \\
\hline Paired test (Intra-group) & $\mathrm{P}<0.001$ & $\mathrm{P}<0.001$ & & \\
\hline
\end{tabular}

Between groups comparison showed, before intervention, the mean scores for breastfeeding performance was not significantly different between two groups $(P=0.7)$. However, after the intervention, it was higher in the interventional group comparing to the control group ( $T$ test; $p<0.001)$. Intra-groups comparison demonstrated, after intervention, the improvement was not seen after 4 months in the control group ( $p=$ 0.6), while there was a significant improvement in the intervention group comparing to before intervention (Paired test; $p<0.001$ ) (Table 3). 
Table 3

The comparison of maternal breastfeeding performance and status before and after intervention in two groups of the study

\begin{tabular}{|c|c|c|c|c|c|c|c|c|}
\hline \multirow{3}{*}{$\begin{array}{l}\text { Groups } \\
\text { The items }\end{array}$} & \multicolumn{4}{|c|}{ Before } & \multicolumn{4}{|c|}{ After } \\
\hline & \multicolumn{2}{|c|}{$\begin{array}{l}\text { Control } \\
(n=38)\end{array}$} & \multicolumn{2}{|c|}{$\begin{array}{l}\text { Intervention } \\
(n=38)\end{array}$} & \multicolumn{2}{|c|}{$\begin{array}{l}\text { Control } \\
(n=38)\end{array}$} & \multicolumn{2}{|c|}{$\begin{array}{l}\text { Intervention } \\
(n=38)\end{array}$} \\
\hline & $\mathbf{n}$ & $\%$ & $\mathbf{n}$ & $\%$ & $\mathbf{n}$ & $\%$ & $\mathbf{n}$ & $\%$ \\
\hline $\begin{array}{l}\text { The mother is quite calm and } \\
\text { comfortable }\end{array}$ & 15 & 39.5 & 18 & 47.4 & 5 & 13.2 & 38 & 100 \\
\hline $\begin{array}{l}\text { The infant's face is in front of the } \\
\text { mother's breast }\end{array}$ & 22 & 57.9 & 19 & 50 & 12 & 31.6 & 38 & 100 \\
\hline $\begin{array}{l}\text { The infant's head and body are in one } \\
\text { direction }\end{array}$ & 16 & 42.1 & 19 & 50 & 12 & 31.6 & 37 & 97.4 \\
\hline $\begin{array}{l}\text { The infant's chin is attached to the } \\
\text { mother's breast }\end{array}$ & 20 & 52.6 & 17 & 44.7 & 16 & 42.1 & 38 & 100 \\
\hline $\begin{array}{l}\text { The infant's hips are in the mother's } \\
\text { arms }\end{array}$ & 18 & 47.4 & 16 & 42.1 & 10 & 26.3 & 38 & 100 \\
\hline $\begin{array}{l}\text { the infant sucks when she/he is } \\
\text { hungry }\end{array}$ & 18 & 47.4 & 22 & 57.9 & 24 & 63.2 & 38 & 100 \\
\hline The infant is properly sucking & 21 & 55.3 & 23 & 60.5 & 22 & 57.9 & 38 & 100 \\
\hline There are signs of flowing milk & 22 & 57.9 & 26 & 68.4 & 27 & 71.1 & 38 & 100 \\
\hline $\begin{array}{l}\text { The mother embraces the infant with } \\
\text { confidence }\end{array}$ & 17 & 44.7 & 18 & 47.4 & 12 & 31.6 & 38 & 100 \\
\hline $\begin{array}{l}\text { There is a face-to-face in maternal- } \\
\text { infant relationship }\end{array}$ & 16 & 42.1 & 19 & 50 & 14 & 36.8 & 38 & 100 \\
\hline $\begin{array}{l}\text { The mother touches the infant while } \\
\text { breastfeeding }\end{array}$ & 16 & 42.1 & 17 & 44.7 & 12 & 31.6 & 36 & 94.7 \\
\hline Breasts are soft after breastfeeding & 22 & 57.9 & 23 & 60.5 & 27 & 71.1 & 32 & 84.2 \\
\hline Nipples have adequate elasticity & 22 & 57.9 & 20 & 52.6 & 19 & 50 & 38 & 100 \\
\hline The skin of the nipple is healthy. & 18 & 47.4 & 23 & 60.5 & 32 & 84.2 & 38 & 100 \\
\hline Breasts look full when breastfeeding. & 21 & 55.3 & 24 & 63.2 & 23 & 60.5 & 38 & 100 \\
\hline $\begin{array}{l}\text { The infant takes both breasts without } \\
\text { difficulty. }\end{array}$ & 16 & 42.1 & 17 & 44.7 & 21 & 55.3 & 38 & 100 \\
\hline $\begin{array}{l}\text { The infant is attentive when } \\
\text { breastfeeding. }\end{array}$ & 22 & 57.9 & 24 & 63.2 & 21 & 55.3 & 38 & 100 \\
\hline
\end{tabular}




\begin{tabular}{|c|c|c|c|c|c|c|c|c|}
\hline \multirow{4}{*}{$\begin{array}{l}\text { Groups } \\
\text { The items }\end{array}$} & \multicolumn{4}{|c|}{ Before } & \multicolumn{4}{|c|}{ After } \\
\hline & \multirow{2}{*}{\multicolumn{2}{|c|}{$\begin{array}{l}\text { Control } \\
(n=38)\end{array}$}} & \multirow{2}{*}{\multicolumn{2}{|c|}{$\begin{array}{l}\text { Intervention } \\
(n=38)\end{array}$}} & \multirow{2}{*}{\multicolumn{2}{|c|}{$\begin{array}{l}\text { Control } \\
(n=38)\end{array}$}} & \multirow{2}{*}{\multicolumn{2}{|c|}{$\begin{array}{l}\text { Intervention } \\
(n=38)\end{array}$}} \\
\hline & & & & & & & & \\
\hline & $\mathbf{n}$ & $\%$ & $\mathrm{n}$ & $\%$ & $\mathbf{n}$ & $\%$ & $\mathbf{n}$ & $\%$ \\
\hline $\begin{array}{l}\text { The infant's mouth is completely } \\
\text { open. }\end{array}$ & 19 & 50 & 21 & 55.3 & 25 & 65.8 & 38 & 100 \\
\hline $\begin{array}{l}\text { The infant's lower lip is turned } \\
\text { outwards }\end{array}$ & 22 & 57.9 & 22 & 57.9 & 30 & 78.9 & 38 & 100 \\
\hline The tongue surrounds the breast & 23 & 60.5 & 23 & 60.5 & 23 & 60.5 & 38 & 100 \\
\hline Cheeks are Hollow and protruding & 19 & 50 & 18 & 47.4 & 22 & 57.9 & 38 & 100 \\
\hline $\begin{array}{l}\text { Most of the areola is seen above the } \\
\text { infant's mouth. }\end{array}$ & 20 & 52.6 & 20 & 52.6 & 23 & 60.5 & 38 & 100 \\
\hline Sucking is slow and deep. & 26 & 68.4 & 24 & 63.2 & 24 & 63.2 & 38 & 100 \\
\hline $\begin{array}{l}\text { The sound of swallowing can be } \\
\text { heard. }\end{array}$ & 20 & 52.6 & 19 & 50 & 27 & 71.1 & 38 & 100 \\
\hline $\begin{array}{l}\text { The infant releases the breasts by } \\
\text { him/herself }\end{array}$ & 21 & 55.3 & 22 & 57.9 & 18 & 47.4 & 38 & 100 \\
\hline $\begin{array}{l}\text { The infant appears to be full after } \\
\text { breastfeeding }\end{array}$ & 21 & 55.3 & 21 & 55.3 & 18 & 47.4 & 38 & 100 \\
\hline Mean \pm SD (Score 0-100) & $\begin{array}{l}54 . \\
38 .\end{array}$ & & $\begin{array}{l}51 \\
33\end{array}$ & & $\begin{array}{l}52 . \\
19 .\end{array}$ & & 99. & 1.66 \\
\hline \multirow[t]{2}{*}{ Paired test (Intra-Group Comparison) } & \multicolumn{4}{|c|}{ Intra-Control group } & \multicolumn{4}{|c|}{ Intra-intervention group } \\
\hline & \multicolumn{4}{|c|}{$P=0.7 ; T=0.4$} & \multicolumn{4}{|c|}{$P<0.0001 ; t=-8.7$} \\
\hline \multirow[t]{2}{*}{$\begin{array}{l}\text { Independent T test (Between Groups } \\
\text { Comparison) }\end{array}$} & \multicolumn{4}{|c|}{$\begin{array}{l}\text { Before (between control and } \\
\text { intervention) }\end{array}$} & \multicolumn{4}{|c|}{$\begin{array}{l}\text { After(between control and } \\
\text { intervention) }\end{array}$} \\
\hline & \multicolumn{4}{|c|}{$P=0.7 ; T=0.27$} & \multicolumn{4}{|c|}{$P<0.0001 ; T=-14.8$} \\
\hline
\end{tabular}

Finding also showed higher frequency of exclusive breastfeeding after 4 months in intervention group comparing to control group after intervention $(p<0.001)($ Table 4$)$. 
Table 4

The comparison of inclusive- and exclusive-breastfeeding of two groups of studies before and after intervention

\begin{tabular}{|c|c|c|c|c|c|c|c|c|}
\hline \multirow{3}{*}{$\begin{array}{l}\text { Groups } \\
\text { Variables }\end{array}$} & \multicolumn{4}{|c|}{ Before } & \multicolumn{4}{|c|}{ After } \\
\hline & \multicolumn{2}{|c|}{$\begin{array}{l}\text { Control }(n= \\
38)\end{array}$} & \multicolumn{2}{|c|}{$\begin{array}{l}\text { Intervention( } \mathrm{n}= \\
\text { 38) }\end{array}$} & \multicolumn{2}{|c|}{$\begin{array}{l}\text { Control }(n= \\
38)\end{array}$} & \multicolumn{2}{|c|}{$\begin{array}{l}\text { Intervention }(n= \\
\text { 38) }\end{array}$} \\
\hline & $\mathrm{n}$ & $\%$ & $\mathrm{n}$ & $\%$ & $\mathbf{n}$ & $\%$ & $\mathrm{n}$ & $\%$ \\
\hline Breast Milk & 10 & 26.3 & 17 & 44.7 & 8 & 21.1 & 32 & 84.2 \\
\hline $\begin{array}{l}\text { Powdered milk or } \\
\text { livestock }\end{array}$ & 3 & 7.9 & 1 & 2.6 & 3 & 7.9 & 5 & 13.2 \\
\hline $\begin{array}{l}\text { Breast milk with other } \\
\text { milks }\end{array}$ & 25 & 65.8 & 20 & 52.6 & 27 & 71.1 & 1 & 2.6 \\
\hline Chi ${ }^{2}$ test & \multicolumn{4}{|c|}{$P=0.2$} & \multicolumn{4}{|c|}{$P<0.001$} \\
\hline
\end{tabular}

\section{Discussion}

This study showed the effectiveness of the fathers' education on breastfeeding continuity and performance. There are many studies showing the effectiveness of educational interventions on promoting breastfeeding. However, there are a few studies have examined the effects of fathers' education on breastfeeding in Iran. Fathers' support of breastfeeding are found to increase duration of breastfeeding (24).

This study shows that the fathers education improves fathers practice in mothers' encouragement and planning for a successful breastfeeding. Studies should majority of fathers willing to participate in reproductive health and perinatal care including prenatal care, labor and postpartum care as well as in promoting breast feeding, however, many of them do not know the ways of their involvement. Especially, they would like to help mothers for the breastfeeding task (25).

In the present study, fathers learned the ways for their involvement in the breastfeeding. They learnt to help through encouragement of mothers for breastfeeding and planning for an appropriate maternal nutrition. The education was concentrated on men's involvement in the household affairs and looking after other children for decreasing daily tasks of nursing mothers, and so free mothers' time for rest and so preparing them for night feeding of the infant. In this study fathers learnt the ways to encourage and plan to achieve a regular and continuous exclusive breastfeeding. There are many intervention studies to promote men's involvement for improving exclusive breastfeeding (26) A review study documented several other ways to engage men for promoting breastfeeding and showed high-intensity strategies engaged men directly during home or health visits by forming men's groups and by working with male community leaders or members to promote exclusive breastfeeding. Low-intensity strategies included large community meetings that included men, and radio messages, and other behavior change materials 
directed towards men (27). Also a study concluded that the most effective breastfeeding support is delivered using a sensitive, coordinated teamwork approach that is responsive to the mother's needs (26).

The results demonstrated that fathers' education improves mothers' breastfeeding performance. It is documented that social support especially the husband support increases self-efficacy in performing health behavior including breastfeeding practice of mothers (14). Also men's education about the involvement in breastfeeding promotion was shown to increase mothers' satisfaction and performance (28). Previous studies demonstrated that the education improves fathers' knowledge and makes a positive attitude towards breast milk (29). Then fathers learnt how to plan and encourage their nursing wife to improve their performance in breastfeeding (30).

Besides this study showed longer continuity in exclusive breastfeeding after the education of fathers. This is inconsistent with results of other studies in brazil and Turkey that showed father's education increase duration of exclusive breast feeding $(29,31)$.There are many problems and barriers for continuity of exclusive breastfeeding such as misbeliefs about "inadequacy of milk for infant", "deforming breast shape", "difficulty for breastfeeding in social settings", "difficulty in breastfeeding for employed mothers" (12). The present study attempted to correct these misbeliefs and also the ways to overcome the difficulties in breastfeeding. Also, education about the importance and benefits of breast milk for maternal and infant's health and helps couples for making appropriate decisions (32).

Finding of the present study showed couples' (Men and women) education about breastfeeding can significantly improve exclusive breastfeeding. This effect can be attributed to the importance of fathers' supportive role in primary stages of postnatal period $(18,20)$. It should be also noted that, male involvement is not only helps to promote maternal-neonatal health but also is a main stage for paternal adaptation (33) and also helps to improve men's health (25). So, maternal-infant health services should be integrated with paternal services and gender based health needs for any society (34).

This study like other experimental studies had a difficulty to prevent drop of subjects during follow up period. The researchers overcame this limitation using continues contact with the participants.

\section{Conclusion}

The study documented the effectiveness of fathers' education about the importance and benefits of breast-milk and breastfeeding as well as the ways of planning and encouraging breastfeeding on improvement of mothers' performance and continuity of exclusive breastfeeding.

This intervention could be also effective on maternal- infant physical and mental health as well as on paternal adaptation with paternal roles and also improves their health. So fathers' education to promote male involvement on breastfeeding promotion intervention is strongly recommended to integrate in maternal health services.

\section{Abbreviations}


Not applicable

\section{Declarations}

\section{Ethics approval and consent to participate}

We obtained written informed consent form all study participants. The Shahid Beheshti University of Medical Sciences Research Ethics Committee (SBMU2.REC.1394.162) have approved this study. Participants will be assured that their privacy will be protected using deidentified data for analysis

\section{Consent for publication}

Not applicable

\section{Availability of data and materials}

The study data available by contacting the correspond author of this paper.

\section{Competing interests}

The authors declare that they have no competing interests

\section{Funding}

This study is part of a master thesis funded by research deputy of Shahid Beheshti University of Medical Sciences, Tehran, Iran.

\section{Authors' contributions}

FP: project administration, writing-review and editing, supervision

MS: project administration, writing-review and editing, supervision

FRF: contributed to the initial draft of the study protocol.

ML: Project development, Data Collection, Manuscript writing.

M R: Project development, Data Collection, Manuscript writing.

All authors have read and approved the final manuscript.

\section{Acknowledgement}

The authors are thankful from the Shahid Beheshti University of Medical Science and the participants in this study. 


\section{References}

1. Wambach K, Spencer B. Breastfeeding and human lactation: Jones \& Bartlett Publishers; 2019.

2. Kramer MS, Kakuma R. Optimal duration of exclusive breastfeeding. Cochrane database of systematic reviews. 2012(8).

3. Duijts L, Jaddoe VW, Hofman A, Moll HA. Prolonged and exclusive breastfeeding reduces the risk of infectious diseases in infancy. Pediatrics. 2010;126(1):e18-e25.

4. Victora CG, Bahl R, Barros AJ, França GV, Horton S, Krasevec J, et al. Breastfeeding in the 21st century: epidemiology, mechanisms, and lifelong effect. The Lancet. 2016;387(10017):475-90.

5. Cai X, Wardlaw T, Brown DW. Global trends in exclusive breastfeeding. International breastfeeding journal. 2012;7(1):12.

6. Behzadifar M, Saki M, Behzadifar M, Mardani M, Yari F, Ebrahimzadeh F, et al. Prevalence of exclusive breastfeeding practice in the first six months of life and its determinants in Iran: a systematic review and meta-analysis. BMC pediatrics. 2019;19(1):384.

7. Dalili H, Shariat M, Nayeri F, Emami Z, Sahebi R, Sahebi L. Exclusive breastfeeding duration and its effect on the health of the children in Iran, a meta analysis. Journal of pediatric nursing. 2019.

8. Collective GB, UNICEF, Organization WH. Global breastfeeding scorecard, 2017: Tracking progress for breastfeeding policies and programmes. World Health Organization. 2017.

9. Lumbiganon P, Martis R, Laopaiboon M, Festin MR, Ho JJ, Hakimi M. Antenatal breastfeeding education for increasing breastfeeding duration. Cochrane Database of Systematic Reviews. 2016(12).

10. Zhu Y, Zhang Z, Ling Y, Wan H. Impact of intervention on breastfeeding outcomes and determinants based on theory of planned behavior. Women and Birth. 2017;30(2):146-52.

11. Stuebe AM, Bonuck K. What predicts intent to breastfeed exclusively? Breastfeeding knowledge, attitudes, and beliefs in a diverse urban population. Breastfeeding Medicine. 2011;6(6):413-20.

12. Ghasemi V, Simbar M, Ghasemi E, Ebadi A, Kiani Z, Mahdizad Keyghobad F, et al. Predictor Factors of Breastfeeding Attitude in Iranian Breastfeeding Mothers: A Cross-Sectional Study. International Journal of Pediatrics. 2019;7(3):9103-13.

13. Patel V. Improving Knowledge, Skills, and Attitudes about Breastfeeding. 2019.

14. Ghasemi V, Simbar M, Banaei M, Saei Ghare Naz M, Jahani Z, Nazem H. The Effect of Interventions on Breastfeeding Self-efficacy by Using Bandura's Theory in Iranian Mothers: A Systematic Review. International Journal of Pediatrics. 2019;7(8):9939-54.

15. Jamehei F, Ostovar A, Javadzade H. Predictors of exclusive breastfeeding among nulliparous Iranian mothers: application of the theory of planned behavior. International Journal of Pediatrics. 2017;5(3).

16. Senghore T, Omotosho TA, Ceesay $\mathrm{O}$, Williams DCH. Predictors of exclusive breastfeeding knowledge and intention to or practice of exclusive breastfeeding among antenatal and postnatal women receiving routine care: a cross-sectional study. International breastfeeding journal. 2018;13(1):9. 
17. Rempel LA, Rempel JK. The breastfeeding team: the role of involved fathers in the breastfeeding family. Journal of Human Lactation. 2011;27(2):115-21.

18. Sihota H, Oliffe J, Kelly MT, McCuaig F. Fathers' experiences and perspectives of breastfeeding: A scoping review. American journal of men's health. 2019;13(3):1557988319851616.

19. Abbass-Dick J, Brown HK, Jackson KT, Rempel L, Dennis C-L. Perinatal breastfeeding interventions including fathers/partners: A systematic review of the literature. Midwifery. 2019.

20. Demontigny F, Gervais C, Larivière-Bastien D, St-Arneault K. The role of fathers during breastfeeding. Midwifery. 2018;58:6-12.

21. Bich TH, Cuong NM. Changes in knowledge, attitude and involvement of fathers in supporting exclusive breastfeeding: a community-based intervention study in a rural area of Vietnam. International journal of public health. 2017;62(1):17-26.

22. Mahesh PKB, Gunathunga MW, Arnold SM, Jayasinghe C, Pathirana S, Makarim MF, et al. Effectiveness of targeting fathers for breastfeeding promotion: systematic review and meta-analysis. BMC Public Health. 2018;18(1):1140.

23. Wang S, Guendelman S, Harley K, Eskenazi B. When Fathers are Perceived to Share in the Maternal Decision to Breastfeed: Outcomes from the Infant Feeding Practices Study II. Maternal and child health journal. 2018;22(11):1676-84.

24. Muelbert M, Giugliani ER. Factors associated with the maintenance of breastfeeding for 6,12 , and 24 months in adolescent mothers. BMC public health. 2018;18(1):675.

25. Simbar M, Nahidi F, Ramezani Tehrani F, Akbarzadeh A. Educational needs assessment for men's participation in perinatal care. EMHJ-Eastern Mediterranean Health Journal, 17 (9), 689-696, 2011. 2011.

26. Rempel LA, Rempel JK, Moore KC. Relationships between types of father breastfeeding support and breastfeeding outcomes. Maternal \& child nutrition. 2017;13(3):e12337.

27. Yourkavitch JM, Alvey JL, Prosnitz DM, Thomas JC. Engaging men to promote and support exclusive breastfeeding: a descriptive review of 28 projects in 20 low-and middle-income countries from 2003 to 2013. Journal of Health, Population and Nutrition. 2017;36(1):43.

28. Abbass-Dick J, Stern SB, Nelson LE, Watson W, Dennis C-L. Coparenting breastfeeding support and exclusive breastfeeding: a randomized controlled trial. Pediatrics. 2015;135(1):102-10.

29. Panahi F, Simbar M, Lotfı R, Rahimzadeh M. The effect of parents' training on their knowledge, attitudes and performance in exclusive breastfeeding up to four months: A randomized clinical trial. The Iranian Journal of Obstetrics, Gynecology and Infertility. 2017;20(5):48-57.

30. Tombeau Cost K, Jonas W, Unternaehrer E, Dudin A, Szatmari P, Gaudreau H, et al. Maternal perceptions of paternal investment are associated with relationship satisfaction and breastfeeding duration in humans. Journal of family psychology. 2018;32(8):1025.

31. Rosane Odeh Susin L, Regina Justo Giugliani E. Inclusion of fathers in an intervention to promote breastfeeding: impact on breastfeeding rates. Journal of Human Lactation. 2008;24(4):386-92. 
32. Asiodu IV, Waters CM, Dailey DE, Lyndon A. Infant feeding decision-making and the influences of social support persons among first-time African American mothers. Maternal and child health journal. 2017;21(4):863-72.

33. Eskandari N, Simbar M, Vedadhir A, Baghestani AR. Paternal adaptation in first-time fathers: a phenomenological study. Journal of reproductive and infant psychology. 2017;35(1):53-64.

34. Simbar M, Rahmanian F, Nazarpour S, Ramezankhani A, Eskandari N, Zayeri F. Design and psychometric properties of a questionnaire to assess gender sensitivity of perinatal care services: a sequential exploratory study. BMC Public Health. 2020;20(1):1-13.

\section{Figures}




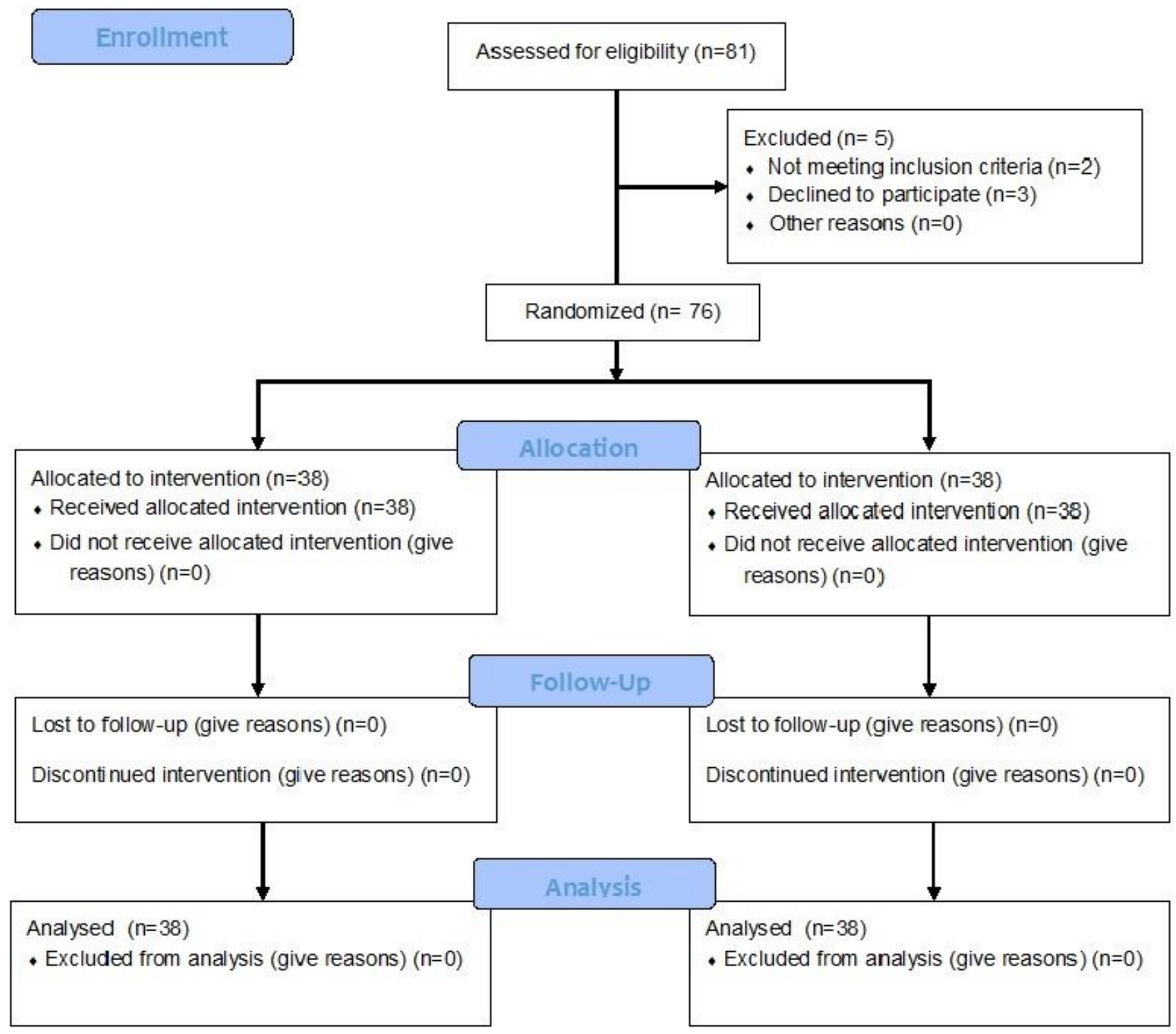

Figure 1: The Consort Flow Chart

\section{Figure 1}

Flow Chart 